\title{
Rod Photoreceptors Avoid Saturation in Bright Light by the Movement of the G Protein Transducin
}

\author{
Rikard Frederiksen, ${ }^{1}$ Ala Morshedian, ${ }^{1}$ Sonia A. Tripathy, ${ }^{1}$ Tongzhou Xu, ${ }^{1}$ Gabriel H. Travis, ${ }^{1}$ \\ (Dordon L. Fain, ${ }^{1,2}$ and (iD)Alapakkam P. Sampath ${ }^{1}$ \\ ${ }^{1}$ Department of Ophthalmology and Jules Stein Eye Institute, University of California, Los Angeles, California 90095-7000, and ${ }^{2}$ Department of \\ Integrative Biology and Physiology, University of California, Los Angeles, California 90095-7239
}

Rod photoreceptors can be saturated by exposure to bright background light, so that no flash superimposed on the background can elicit a detectable response. This phenomenon, called increment saturation, was first demonstrated psychophysically by Aguilar and Stiles and has since been shown in many studies to occur in single rods. Recent experiments indicate, however, that rods may be able to avoid saturation under some conditions of illumination. We now show in ex vivo electroretinogram and single-cell recordings that in continuous and prolonged exposure even to very bright light, the rods of mice from both sexes recover as much as $15 \%$ of their dark current and that responses can persist for hours. In parallel to recovery of outer segment current is an $\sim 10$-fold increase in the sensitivity of rod photoresponses. This recovery is decreased in transgenic mice with reduced light-dependent translocation of the G protein transducin. The reduction in outer-segment transducin together with a novel mechanism of visual-pigment regeneration within the rod itself enable rods to remain responsive over the whole of the physiological range of vision. In this way, rods are able to avoid an extended period of transduction channel closure, which is known to cause photoreceptor degeneration.

Key words: adaptation; G protein; retina; rod photoreceptor; saturation; visual pigment

\section{Significance Statement}

Rods are initially saturated in bright light so that no flash superimposed on the background can elicit a detectable response. Frederiksen and colleagues show in whole retina and single-cell recordings that, if the background light is prolonged, rods slowly recover and can continue to produce significant responses over the entire physiological range of vision. Response recovery occurs by translocation of the $G$ protein transducin from the rod outer to the inner segment, together with a novel mechanism of visual-pigment regeneration within the rod itself. Avoidance of saturation in bright light may be one of the principal mechanisms the retina uses to keep rod outer-segment channels from ever closing for too long a time, which is known to produce photoreceptor degeneration.

\section{Introduction}

There are two kinds of photoreceptors in vertebrate retina: rods with quantum sensitivity mediating vision in dim light; and less

Received Nov. 6, 2020; revised Jan. 21, 2021; accepted Jan. 26, 2021.

Author contributions: R.F., G.L.F., and A.P.S. designed research; R.F., A.M., S.A.T., and T.X. performed research; R.F., A.M., S.A.T., and T.X. analyzed data; R.F., A.M., G.H.T., G.L.F., and A.P.S. edited the paper; R.F., G.L.F., and A.P.S. wrote the paper.

This work was supported by National Eye Institute, National Institutes of Health Grants EY29817 to A.P.S., EY001844 to G.L.F., and EY024379 to G.H.T.; Research to Prevent Blindness USA unrestricted grant to the UCLA Department of Ophthalmology; and National Eye Institute Core Grant EY00311 to the Jules Stein Eye Institute. G.H.T. is the Charles Kenneth Feldman Professor of Ophthalmology at UCLA. We thank Ekaterina Bikovtseva for technical assistance; Marie Burns for providing a Gnat2 ${ }^{-1-}$ mating pair; Carter Cornwall and Jürgen Reingruber for comments on the manuscript; and Khris Griffis for writing the data analysis package Iris DVA.

The authors declare no competing financial interests.

Correspondence should be addressed to Gordon L. Fain at gfain@ucla.edu or Alapakkam P. Sampath at asampath@jsei.ucla.edu.

https://doi.org/10.1523/JNEUROSCI.2817-20.2021

Copyright $\odot 2021$ the authors sensitive but kinetically more rapid cones, which permit rapid estimation of light intensity enabling wavelength discrimination and sensitivity to motion. Aguilar and Stiles (1954) first showed that rods saturate and no longer function when exposed to bright background light. They measured light adaptation in human observers under conditions that maximized the contribution of rods and minimized those of cones, and they found that rod sensitivity decreased according to a Weber-Fechner relation in dim backgrounds; but as the light was made brighter, sensitivity fell at a much more rapid rate. Eventually, the observer could no longer use rods to detect any flash superimposed on the background. Subsequent results have confirmed these observations in human (see Makous, 2003) and behaving mice (Naarendorp et al., 2010), and recordings from single rods in a variety of vertebrate species show a similar effect (Fain, 1976; Tamura et al., 1991; Mendez et al., 2001; Makino et al., 2004; Morshedian and Fain, 2017). Saturation of rods is one of the pillars of our understanding of the duplex retina and is described in any elementary 
treatment of visual behavior (see, e.g., https://webvision.med.utah. edu/book/part-viii-psychophysics-of-vision/light-and-darkadaptation/). Rods set the visual threshold in dim light, but rod signals are then thought to diminish as the light is made brighter to permit the kinetically faster cones to mediate detection of more rapidly changing features of the visual scene.

This simple scheme has recently been challenged by work showing that rods continue to respond in bright light provided the background illumination is maintained for a sufficiently long duration (Tikidji-Hamburyan et al., 2017; Borghuis et al., 2018). To provide clarification of this phenomenon, and to characterize its nature and mechanism, we have undertaken a detailed study of mouse rod responses in bright background light. We show in ex vivo ERG and single-cell recordings that rods indeed recover a significant fraction of their photocurrent during long-duration light exposure and continue to respond for several hours under these conditions, even in the absence of the retinal pigment epithelium (RPE) and when no visual pigment is calculated to remain. Our experiments indicate that avoidance of saturation is a consequence primarily of the light-dependent translocation of the $G$ protein transducin from the rod outer segment to the rod inner segment, which reduces the gain of phototransduction and allows outer-segment channels to reopen (Sokolov et al., 2002). This process, together with the recovery of sufficient visual pigment to enable continued excitation of the phototransduction cascade, can make it possible for rods to maintain responsivity over the entire physiological range of vision and to avoid a prolonged period of channel closure, which is known to produce photoreceptor degeneration (Fain, 2006).

\section{Materials and Methods}

Animals. This study was conducted in accordance with the recommendations of the Guide for the care and use of laboratory animals of the National Institutes of Health, and the Association for Research in Vision and Ophthalmology Statement for the Use of Animals in Ophthalmic and Vision Research. The animal-use protocol was approved by the University of California, Los Angeles, Animal Research Committee (Protocol no. 14-005). Euthanasia was performed by cervical dislocation. Every effort was made to minimize pain and discomfort in mice used in this study.

All mice were reared under $12 \mathrm{~h}$ cyclic light. Gnat $2^{-1-}$ mice were generously provided by Marie Burns. This strain and the details of its genotyping have been previously described (Ronning et al., 2018). Gnat $1^{-/-} ; A 3 C^{+}$mice were provided by Nikolai Artemyev and bred with Gnat $2^{-1-}$ mice to produce Gnat $2^{-1-} ;$ Gnat $1^{-1-} ; A 3 C^{+}$mice used in this study. Details about the Gnat $1^{-1-} ; A 3 C^{+}$strain and its genotyping can be found in a previous publication (Majumder et al., 2013). Genotyping of these strains was performed by Transnetyx $\left(\right.$ Gnat $\left.2^{-I-}\right)$ and Laragen $\left(\right.$ Gnat $\left.^{-1-} ; A 3 C^{+}\right)$. WT (129/SV-E) mice were purchased from Charles River. All animals used in this study were between 1 and 6 months old. Both sexes were used in approximately equal numbers.

Dissections and tissue preparation. Eyes from mice were enucleated in darkness by means of infrared image converters (ITT Industries). The anterior portion of the eye was cut, and the lens and cornea were removed in darkness with a dissection microscope (Carl Zeiss) equipped with infrared image converters (B.E. Meyers) under infrared illumination. The retina was isolated from the eyecup, and the RPE was removed with fine tweezers. Tissue was stored at $32^{\circ} \mathrm{C}$ in a light-tight container in Ames' medium supplemented with $1.9 \mathrm{~g} / \mathrm{l} \mathrm{NaHCO}_{3}$ and equilibrated with $95 \% \mathrm{O}_{2} / 5 \% \mathrm{CO}_{2}$ at $\mathrm{pH} 7.4$.

Solutions. In all experiments, except for tissue preparation for highperformance liquid chromatography (HPLC) analysis (see below), the retinal tissue was superfused at a rate of $4 \mathrm{ml} / \mathrm{min}$ with Ames' medium buffered with $\mathrm{NaHCO}_{3}$ and equilibrated with $95 \% \mathrm{O}_{2} / 5 \% \mathrm{CO}_{2}$ at $\mathrm{pH}$ 7.4. The osmolarity of the medium was adjusted to $284 \mathrm{mOsm}$ with a vapor-pressure osmometer (Wescore). Temperature was maintained at $35^{\circ} \mathrm{C}-38^{\circ} \mathrm{C}$ with an automatic temperature controller (Warner Instruments). In trans-retinal ERG recordings, the solution was supplemented with $40 \mu \mathrm{M}$ DL-2-amino-4-phosphonobutyric acid (Tocris Bioscience), and $100 \mu \mathrm{M} \mathrm{BaCl}_{2}$ (Sigma Millipore) to isolate the photoreceptor response. The electrode solution used in the pipettes in the suction-electrode experiments, and in the electrode canals of the ERG chamber, contained the following (in $\mathrm{mm}$ ): $93 \mathrm{NaCl}, 2.1 \mathrm{KCl}, 2.6$ $\mathrm{CaCl}_{2}, 1.8 \mathrm{MgCl}_{2}, 2.0 \mathrm{NaHCO}_{3}$, and 10.8 HEPES at pH 7.4.

Trans-retinal (ERG) recording. The retina was mounted with the photoreceptor side facing up on filter paper (Millipore, $0.45 \mu \mathrm{m}$ pore size), which was glued to the bottom compartment of a perfusion chamber (Vinberg et al., 2014). One $\mathrm{Ag} / \mathrm{AgCl}$ electrode was mounted in contact with solution on the ganglion-cell side of the retina, and another was situated in contact with the solution bathing the photoreceptors. The electrodes were connected to a DP-311 differential amplifier (Warner Instruments).

Stimulus and background light were delivered with a dual OptoLED light source (Cairn Research) coupled to a custom-built, dual-pathway, optical system for uniform, calibrated illumination of the preparation. The stimulus light path had a $505 \mathrm{~nm}$ LED that was attenuated by absorptive neutral density filters. Background light was provided by a white LED coupled to $10 \mathrm{~nm}$ bandwidth interference filters and attenuated by absorptive neutral-density filters. The beams were combined with a beam-splitter prism. The optical system had a circular field-stop aperture, which was in focus in the plane of the preparation, providing a uniform illumination of the entire retina. All optical components were purchased from Thorlabs. The intensities of the test and background lights were calibrated with a photodiode (Graseby Optronics) connected to a PDA200C photodiode amplifier (Thorlabs). Recordings were lowpass filtered at $100 \mathrm{~Hz}$ and digitized at $1 \mathrm{kHz}$ with a NI USB-6365, X Series DAQ Device (National Instruments). Data were collected with the MATLAB-based (MathWorks) acquisition package and software Symphony Data Acquisition System (open source, https://open-ephys. org/symphony/). Data analysis and plotting were done with a combination Iris DVA custom MATLAB data analysis package (open source, https://github.com/sampath-lab-ucla/IrisDVA), MATLAB, LabVIEW (National Instruments), and OriginPro Graphing and Analysis software (OriginLab).

Suction-electrode recording. The retina was chopped into small pieces, which were then transferred to our recording chamber in darkness with the aid of infrared image converters. Single rod outer-segment responses were recorded at $35^{\circ} \mathrm{C}-38^{\circ} \mathrm{C}$ with the suction-electrode technique (Baylor et al., 1979; Morshedian et al., 2018). Light was delivered with an OptoLED optical system (Cairn Research). Outer-segment membrane current was recorded with a patch-clamp amplifier (Axopatch 200A; Molecular Devices), low-pass filtered at $30 \mathrm{~Hz}$ with an eight-pole Bessel filter (Kemo Limited Electronic Filters), and sampled at $100 \mathrm{~Hz}$. Data were digitized with Clampex, version 8.0 (Molecular Devices), and were analyzed with Origin Pro (OriginLab).

Microspectrophotometry. Spectral absorbance measurements were made with a custom-built single-beam microspectrophotometer (MSP), which was modeled after an instrument used in previous publications (Frederiksen et al., 2012, 2016; Nymark et al., 2012). In brief, a measurement beam of monochromatic light was produced by a xenon-arc light source coupled to a scanning monochromator (Cairn Research). Before reaching the preparation, the beam was polarized with a GlanThompson prism mounted on a rotating stage, so that absorption spectra could be measured with the polarization of the incident measuring beam either parallel to the plane of the intracellular disks of the rods (T polarization) or parallel to the long axis of the outer segment (L polarization). All measurements reported here were made with $\mathrm{T}$ polarization. The size of the measurement beam was set with an adjustable slit (field stop) in the optical path. This slit was brought into focus at the plane of the preparation with a condenser lens (Ultrafluar Kondenser, Carl Zeiss), mounted on a piezo-electric driver (Physik Instrumente), and slaved to the monochromator to correct for chromatic aberration. In these experiments, the measuring beam was adjusted to be a square with a side of $\sim 6 \mu \mathrm{m}$. Transmitted light was 
collected through a Nikon $60 \times$ objective and a photomultiplier tube (Hamamatsu Photonics) and digitized by a National Instruments Mseries DAQ Device (National Instruments). The instrument was controlled by LabVIEW software (National Instruments).

A retinal piece was gently flat-mounted with forceps onto a quartz coverslip window in the bottom of a 2-mm-deep Plexiglas recording chamber with the photoreceptors facing upwards. A slice anchor was placed on top of the tissue to keep it stable throughout the experiment. The recording chamber was mounted on the stage located in the beam path of the MSP. The retinal tissue was superfused at a rate of $4 \mathrm{ml} / \mathrm{min}$ with Ames' medium buffered with $\mathrm{NaHCO}_{3}$ and equilibrated with $95 \%$ $\mathrm{O}_{2} / 5 \% \mathrm{CO}_{2}$. Temperature was maintained at $35^{\circ} \mathrm{C}-37^{\circ} \mathrm{C}$. Absorption spectra were measured from a region of the retina along its edge where outer segments could be seen protruding and perpendicular to the light beam. The measured area contained predominantly rods as evinced by the absorbance spectrum. We made measurements over the wavelength range of $350-700 \mathrm{~nm}$ with $2 \mathrm{~nm}$ resolution. The absorbance spectrum was calculated according to Beers' Law as follows:

$$
O D=\log _{10} \frac{I_{i}}{I_{t}}
$$

where $O D$ is the optical density, $I_{i}$ is the light transmitted through a cellfree space adjacent to the outer segments, and $I_{t}$ is the light transmitted through the tissue. Because the total absorption of rods mounted on their side is small, the absorbance $(O D)$ is very nearly proportional to rhodopsin concentration. To increase the signal-to-noise ratio, 10 sample scans and 20 baseline scans were averaged in each measurement. The amount of bleaching produced per measurement of 10 spectral scans was negligible and below the detection limit of the instrument. All absorbance spectra were baseline corrected. Data were analyzed with LabVIEW (National Instruments) programs and OriginPro Graphing and Analysis software (OriginLab).

HPLC analysis of retinoids. The dissected retinae were transferred to a $35 \mathrm{~mm}$ Petri dish containing $5 \mathrm{ml}$ Ames' medium buffered by HEPES $(2.38 \mathrm{~g} / \mathrm{L})$ at $\mathrm{pH} 7.4$, and were bleached in the optical path of the ERG setup. Two retinae from each mouse were pooled as one sample in a tissue collection tube, immediately flash-frozen in liquid nitrogen, and stored at $-80^{\circ} \mathrm{C}$ in the dark until analyzed.

Retinoids from treated mouse retinae were extracted and analyzed under dim red light as previously described (Radu et al., 2008; Kaylor et al., 2017; Morshedian et al., 2019). On the day of extraction, the tissue was gently thawed, and each sample was homogenized with a glass-glass homogenizer in $500 \mu \mathrm{l}$ of $2 \mathrm{~m}$ hydroxylamine hydrochloride (in $1 \times$ PBS, $\mathrm{pH}$ 7.0-7.2). The homogenate of each sample was kept on ice until all the samples were homogenized, and it was then transferred to a borosilicate test tube containing $25 \mu \mathrm{l} 5 \%$ SDS and $50 \mu \mathrm{l}$ brine, mixed. Another $500 \mu 11 \times$ PBS per sample was used to rinse the original tissue collection tube and the homogenizer, and the rinsate was combined with the homogenate. Each sample was then mixed and incubated at room temperature for $15 \mathrm{~min}$. Subsequently, $2 \mathrm{ml}$ methanol per sample was added, and each sample was extracted twice with $2 \mathrm{ml}$ hexane/time by vortexing and centrifugation at $3500 \times g$ for $5 \mathrm{~min}$. The hexane phases were collected and dried under a stream of nitrogen gas. The extracted retinoids of each sample were redissolved in $100 \mu \mathrm{l}$ hexane (chilled on ice) and analyzed by normal-phase HPLC with a $0.14 \%-10 \%$ dioxane gradient in hexane at $2 \mathrm{ml} / \mathrm{min}$ in an Agilent 1100 series liquid chromatograph with a photodiode-array detector and an Agilent ZORBAX Rx-SIL column $(4.6 \times 250 \mathrm{~mm}, 5 \mu \mathrm{m})$. Each retinoid peak was identified by its spectrum and elution time with reference to authenticated retinoid standards. Retinoid quantitation was performed by comparing the sample peak areas to calibration curves established from standards. Retinals were quantitated by summation of their corresponding syn- and anti-oximes.

Estimate of pigment regeneration. To estimate the amount of visual pigment being regenerated in the rods, we constructed a simple equilibrium model. We assumed that all bleaching and regeneration occurred within the rod and that both are first-order processes driven by light. Rhodopsin (Rho) is bleached by light with a photosensitivity, $P$ (Dartnall, 1968; Woodruff et al., 2004). The bleached rhodopsin yields opsin (Ops) and all-trans retinal (atRAL) which remain in proximity (for instance as photoproducts of bleaching). While in this state, atRAL in some form is hypothesized to absorb a photon $(\phi)$ and isomerize to 11-cis retinal, thus regenerating rhodopsin with a light-dependent rate constant $k_{r}$ as follows:

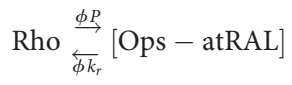

The [Ops-atRAL] in this formulation could be an intermediate of bleaching (e.g., Meta III), but could also be opsin together with atRAL, free or bound to phosphatidylethanolamine (PE) (Kaylor et al., 2017). These relations yield the following equations:

$$
\frac{d \rho}{d t}=-\rho \phi P+\mu \phi k_{r}
$$

$$
\frac{d \mu}{d t}=\rho \phi P-\mu \phi k_{r}-\mu k_{d}
$$

where $\rho$ and $\mu$ represent the normalized concentrations of [Rho] and [Ops-atRAL], and $k_{d}$ is the rate constant of decay of an intermediate of bleaching or removal of atRAL, for example, by leaching out of the outer segment. Equations $2 \mathrm{a}$ and $2 \mathrm{~b}$ were solved numerically with the scipy. integrate.odeint Python package and fitted to the data in Figure $6 B$ with the scipy.lmfit Python package. The solution to Equation 2a gives $1-F$ in Equation 5. The initial conditions for [Rho] and [Ops-atRAL] were set to 1 and 0 , and we used a photosensitivity of rhodopsin of $\mathrm{P}=5.7 \times$ $10^{-9} \mu \mathrm{m}^{2}$ (Woodruff et al., 2004; Nymark et al., 2012). The best-fitting rate constant for decay was found to be $k_{d}=2.0 \times 10^{-4} \mathrm{~s}^{-1}$, which is $\sim 20$ times slower than the rate constant of Meta III decay in WT mouse rods (Nymark et al., 2012; Frederiksen et al., 2016). The value obtained for $k_{r}$ was $1.8 \times 10^{-11} \mu \mathrm{m}^{2}$.

Experimental design and statistical analysis. Data are presented as mean \pm SEM. Sample sizes are indicated as $n$ in the figure legends. For ERG recordings, the sample was a retinal piece from a single mouse. For suction-electrode recording, $n$ indicates single rods. For HPLC analysis, one sample constituted 2 retinae from a single animal. The fitting of models to data was done with OriginPro Graphing and Analysis software (OriginLab), except in Figure $6 B$ (see Estimate of pigment regeneration).

\section{Results}

\section{Rod responses in bright continuous light}

We recorded rod-mediated signals from isolated, whole mouse retina to maximize the signal-to-noise ratio of the recording. To eliminate signals from cones and other retinal cells, we used retinae from Gnat $2^{-1-}$ mice lacking the gene for cone transducin (Ronning et al., 2018), and we perfused the retina with $40 \mu \mathrm{M}$ DL-2-amino-4-phosphonobutyric acid to block bipolar-cell responses and $100 \mu \mathrm{M} \mathrm{BaCl}$ to eliminate currents from Müller glia (see Materials and Methods) (Vinberg et al., 2014). We first recorded dark-adapted (DA) responses to a series of flashes with light of increasing intensity, which are given in the first column of Figure 1. We then recorded responses to a similar family of flashes immediately after turning on a background light (indicated as time $0 \mathrm{~min}$ ) and at various times during continuous background-light exposure. The background light was provided by an LED source with its peak at $560 \mathrm{~nm}$ (see Materials and Methods). Light intensities are expressed as equivalent photons at the $\lambda_{\max }$ of the rod pigment, designated as $\phi$. The first row shows results at a background intensity of $1.3 \times 10^{4} \phi \mu \mathrm{m}^{-2} \mathrm{~s}^{-1}$, which we estimate initially to produce $\sim 5000$ bleached rhodopsin molecules $\left(\mathrm{Rh}^{*}\right)$ per rod per second and is near the intensity we and others have reported to produce saturation in single rods 


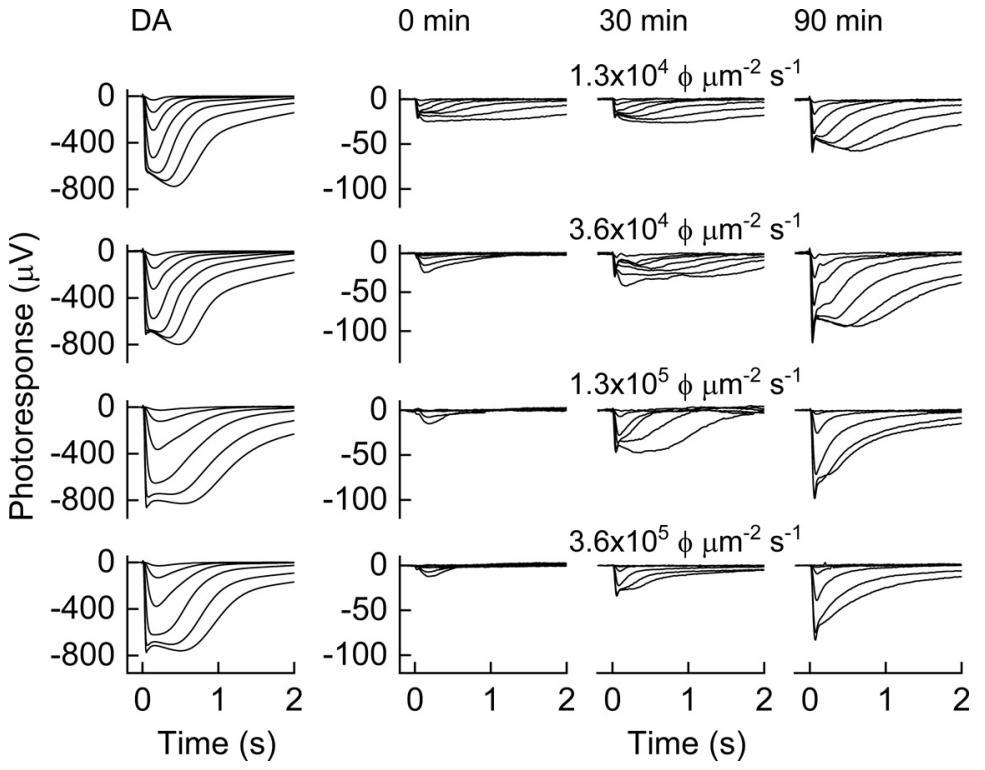

Figure 1. Representative trans-retinal (ERG) recordings of isolated rod responses to flashes of $505 \mathrm{~nm}$ light in DA Gnat2 $^{-1-}$ mouse retinae, immediately $(0 \mathrm{~min}), 30 \mathrm{~min}$, and $90 \mathrm{~min}$ after the onset of a $560 \mathrm{~nm}$ background light. Background light intensity is expressed in $\phi \mu \mathrm{m}^{-2} \mathrm{~s}^{-1}$, which are photons effective at the $\lambda_{\max }$ of mouse rhodopsin at $503 \mathrm{~nm}$ (see Fig. 5). The $505 \mathrm{~nm}$ flashes (in $\phi \mu \mathrm{m}^{-2}$ ) were as follows: $0.80,4.8,19,72,2.5 \times 10^{2}, 7.7 \times 10^{2}$, and $2.3 \times 10^{3}$ (DA before $1.3 \times 10^{4}$ and $3.6 \times 10^{4} \phi \mathrm{um}^{-2} \mathrm{~s}^{-1}$ background); $1.2,6.5,53,2.5 \times 10^{2}$, and $7.1 \times 10^{2}$ (DA before $1.3 \times 10^{5}$ and $3.6 \times 10^{5} \phi \mu \mathrm{m}^{-2} \mathrm{~s}^{-1}$ background); $1.6 \times 102,9.6 \times 10^{2}, 3.8 \times 10^{3}, 1.4 \times 10^{4}, 4.9 \times 10^{4}$, $1.5 \times 10^{5}$, and $4.6 \times 10^{5}\left(1.3 \times 10^{4} \phi \mu^{-2} \mathrm{~s}^{-1}\right.$ background $) ; 1.6 \times 10^{3}, 9.6 \times 10^{3}, 3.8 \times 10^{4}, 1.4 \times 10^{5}, 4.9 \times 10^{5}$, $1.5 \times 10^{6}, 4.5 \times 10^{6}\left(3.6 \times 10^{4} \phi \mu \mathrm{m}^{-2} \mathrm{~s}^{-1}\right.$ background) $; 4.7 \times 10^{3}, 2.1 \times 10^{4}, 7.5 \times 10^{4}, 3.0 \times 10^{5}, 1.2 \times$ $10^{6}, 3.4 \times 10^{6}\left(1.3 \times 10^{5}\right.$ and $3.6 \times 10^{5} \phi \mu \mathrm{m}^{-2} \mathrm{~s}^{-1}$ background $)$.

(Mendez et al., 2001; Morshedian et al., 2018). The following three rows show similar experiments at brighter backgrounds. At time 0 , beginning immediately after turning on the background, we recorded a response-intensity series and could detect small responses to incremental flashes with maximum amplitudes of $15-25 \mu \mathrm{V}$ for each of the background intensities we used, $\sim 2 \%-$ $3 \%$ of the DA maximum amplitude. Since in suction-electrode recordings from the rod outer segment the maximum dark current are typically 15-20 pA (Field and Rieke, 2002; Gross et al., 2012; Morshedian et al., 2018), responses recorded from single rods at time 0 would have been $<1 \mathrm{pA}$ in amplitude and difficult to detect, explaining why rods have previously been assumed to be completely saturated. When, however, the background light was left on for many minutes, the maximum amplitude of the response grew and at 90 min could become as large as $100 \mu \mathrm{V}$, or $>10 \%$ of the maximum amplitude recorded before background illumination.

To confirm that light-evoked responses could be recorded from single rods, we made suction-electrode recordings under similar conditions. Figure $2 A$ shows averaged DA responses from rods recorded before the presentation of a background of $10^{6} \phi \mu \mathrm{m}^{-2} \mathrm{~s}^{-1}$, even brighter than the brightest background used in Figure 1. We then turned on the illumination and continued recording from these same rods for the times indicated in Figure $2 B$. At each time, we gave the same flash $\left(6.1 \times 10^{6} \phi\right.$ $\mu \mathrm{m}^{-2}$ ), which was the brightest our suction-electrode photostimulator could deliver. Initially, responses were very small but gradually grew over $30 \mathrm{~min}$ and averaged nearly $0.5 \mathrm{pA}$, or $\sim 3 \%$ of the average amplitude in darkness. This value is approximately the same as the percent amplitude we recorded after $30 \mathrm{~min}$ in the brightest background of Figure 1. We believe this amplitude to be a lower limit because the waveform of the response suggests that even larger responses could have been evoked by brighter flashes, and because mouse rods recorded with suction electrodes typically lose some of their circulating current with time during a recording.

\section{Changes in sensitivity and maximum amplitude}

To provide a more quantitative description of the time course of the change in rod responsivity during prolonged background exposure, we have plotted response-intensity curves in Figure $3 A, B$ for the background intensity of $1.3 \times 10^{5}$ $\phi \mu \mathrm{m}^{-2} \mathrm{~s}^{-1}$ from Figure 1. The curves in Figure $3 B$ show responses in the presence of the background on an expanded ordinate. All of the data have been fitted to a Michaelis-Menten curve, as follows:

$$
R=R_{\max } \frac{\phi}{\phi+\phi_{1 / 2}}
$$

where $R$ is the response amplitude in $\mu \mathrm{V}$, $R_{\max }$ is the best-fitting maximum amplitude of $R, \phi$ is the number of incident photons in the flash per square micron, and $\phi_{1 / 2}$ is the best-fitting value of $\phi$ at $R$ $=1 / 2 R_{\max }$ (half-saturation constant). The values of the best-fitting parameters are given in the legend to Figure 3. These data show that, from 15 to $90 \mathrm{~min}, \phi_{1 / 2}$ varied within a narrow range from $\sim 5 \times 10^{4}$ to $2 \times 10^{5} \phi \mu \mathrm{m}^{-2}$, at first decreasing at 30 and $45 \mathrm{~min}$ and then increasing again at $60-90 \mathrm{~min}$, perhaps reflecting a slow loss in sensitivity. During these small changes in the half-saturation constant, $R_{\max }$ monotonically increased, reaching its maximum value at $\sim 75 \mathrm{~min}$.

In Figure $3 C, D$, we plot changes in the maximum amplitude and sensitivity for all four background light intensities from Figure 1. Because in some measurements (e.g., the 0 min data in Fig. $3 B$ ), we could not accurately determine $R_{\max }$ with even the brightest flash from our photostimulator, we estimated flash sensitivity as response amplitude per incident light at the illumination necessary to give a response that was $10 \%$ of the largest voltage we could measure for any set of data at a given time and background intensity. We chose the value of $10 \%$ because it was large enough to measure accurately yet still within the near-linear range of the response-intensity curve. The data in Figure $3 C$ confirmed the results of Figure $3 B$, showing that $R_{\text {max }}$ grew monotonically during background light exposure. The time-dependent increase in $R_{\max }$ was substantially greater for the brighter backgrounds than for the dimmest. Similarly, rod sensitivities $\left(S_{F} / S_{F}^{D A}\right)$ increased between 0 and $45 \mathrm{~min}$ of background exposure for all but the dimmest light intensities, plateauing between 60 and $90 \mathrm{~min}$ (Fig. 3D).

These data pose two questions. (1) How can sensitivity and $R_{\text {max }}$ both increase from 0 to $45 \mathrm{~min}$ in the presence of constant background light, and why is the extent of increase smaller for the dimmest light than for the brighter intensities? (2) How can sensitivity between 60 and 90 min remain nearly constant, even in the brightest background? We can calculate the fraction of pigment bleached in these experiments from the photosensitivity equation as follows: 


$$
F=1-e^{-\phi P t}
$$

where $F$ is the fraction bleached, $\phi$ is the light intensity in incident photons $\mu \mathrm{m}^{-2} \mathrm{~s}^{-1}$ at the $\lambda_{\text {max }}$ of the photopigment, and $P$ is the photosensitivity for mouse rhodopsin of $5.7 \times 10^{-9}$ $\mu \mathrm{m}^{2}$ (Woodruff et al., 2004; Nymark et al., 2012). The fraction of pigment remaining is $1-$ $F$. After a 90 min exposure to $3.6 \times 10^{5}$ photons $\mu \mathrm{m}^{-2} \mathrm{~s}^{-1}$, Equation 2 predicts that a single rod in the absence of regeneration would have $\sim 2$ $\times 10^{-5}$ of its normal complement of rhodopsin, or $\sim 1200$ rhodopsin molecules. Since a single mouse rod has $\sim 800$ disks (Nickell et al., 2007), there would be on average 1.5 rhodopsin molecules per disk. In experiments not shown, we have exposed rods for as long as $4 \mathrm{~h}$ at this intensity and at $10^{6}$ incident photons $\mu \mathrm{m}^{-2} \mathrm{~s}^{-1}$, and rods continue to respond much as in Figure 1. Clearly, some mechanism must exist under these experimental conditions for regenerating rhodopsin (Tikidji-Hamburyan et al., 2017).

\section{Role of transducin translocation}

The intensity dependences of the increase in response amplitude and sensitivity appear similar to those required for the light-induced translocation of transducin from the rod outer segment to the inner segment (Sokolov et al., 2002; Lobanova et al., 2007). Moreover, for the three brighter backgrounds in Figure $3 D$, sensitivity increased by a factor of $\sim 10$ and $R_{\max }$ by a factor of $\sim 5$, consistent with a small fraction of transducin still remaining in the outer segment after translocation is complete (Sokolov et al., 2002). A reduction of outer-segment transducin concentration would decrease the gain of phototransduction. This decrease in gain could allow rods to avoid saturation by decreasing activation of the cGMP phosphodiesterase, which would increase the free concentration of cyclic GMP and augment the circulating current and $R_{\max }$. The increase in $R_{\max }$ could in turn explain most of the increase in sensitivity.

To explore a possible role of transducin translocation in changes in rod sensitivity and response amplitude in background light, we used the $A 3 C^{+}$mouse (Majumder et al., 2013). In this animal, the normal Gnat1 gene for the transducin $\alpha$ subunit $\mathrm{G} \alpha_{\mathrm{t}}$ was substituted with $A 3 C^{+}$-Gnat1, which introduces an additional, artificial S-palmitoylation site on $\mathrm{G} \alpha$. This third palmitoylation site increases the affinity of $\mathrm{G} \alpha_{\mathrm{t}}$ for outer-segment disk membranes and impedes $\mathrm{G} \alpha$ trom dissociating during light stimulation. As a result, only about half as much transducin moves to the inner segment in the $A 3 C^{+}$mice compared with control animals during continuous light exposure (Majumder et al., 2013).

The results in Figure 4 show that this reduction in transducin translocation, though partial and incomplete, has nevertheless a significant effect on the changes in sensitivity and $R_{\max }$. Figure $4 A$ shows responses recorded from a Gnat $^{-1-} ;$ Gnat $^{-1-} ; A 3 C^{+}$ retina, first in darkness and then after exposure to $3.1 \times 10^{5} \phi$ $\mu \mathrm{m}^{-2} \mathrm{~s}^{-1}$. Responses before presentation of the background were somewhat smaller than in a WT retina (Fig. 1), perhaps in part because the Gnat $1^{-/-} ;$Gnat $^{-I-} ; A 3 C^{+}$mouse has only $80 \%$ of the transducin as the Gnat $1^{+/+} ;$Gnat $2^{-/-}$mouse, and perhaps also because Gnat $1^{-1-} ;$ Gnat $2^{-1-} ; A 3 C^{+}$mice are known to undergo slow degeneration (Majumder et al., 2013). The sensitivity and waveform of the responses were, however, nearly unaltered. Responses in the presence of the background light were almost undetectable immediately after turning on the light and continued to be smaller, even after correction for the difference of current in darkness, growing much more slowly in amplitude than in a Gnat $2^{-1-}$ retina.

In Figure $4 B, C$, we compare the mean changes in the values $R_{\max }$ and sensitivity for Gnat $1^{-/-} ;$Gnat $2^{-1-} ; A 3 C^{+}$(black symbols) and $G n a t 2^{-l-}$ retinae (red symbols). Nearly all of the increases we observed in Figure 3 have been greatly reduced. Although increases could still be observed, they were smaller than we might have expected, given that nearly half of transducin continues to translocate in these animals. If we had prevented all of the transducin from moving, we think it possible that rods would have remained completely unresponsive in bright backgrounds.

\section{Rhodopsin bleaching}

To investigate possible mechanisms of rhodopsin regeneration, we first measured its concentration directly with MSP during exposure to the various background lights we used in previous experiments. The measuring beam was focused onto a group of rod outer segments lying on their sides, as described previously (Nymark et al., 2012). The background exposure was initiated and then briefly turned off at set times so that the MSP measurements could be made. The total light exposure produced by the MSP measurement itself was small and did not affect the 

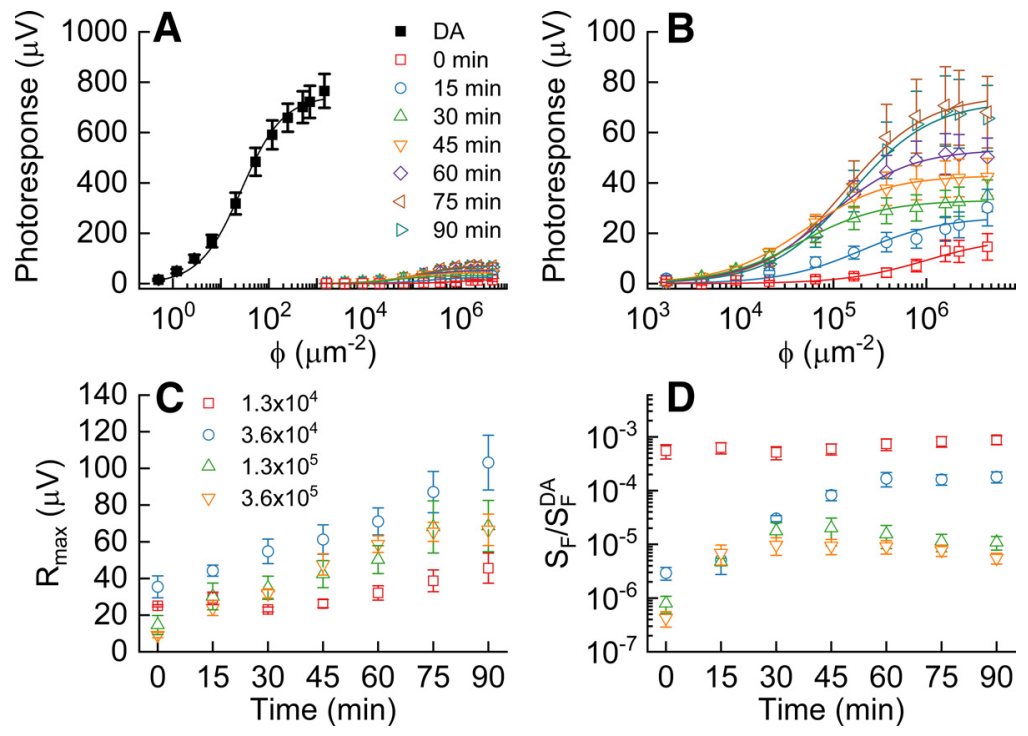

Figure 3. Response amplitude and sensitivity of rods in background light. $\boldsymbol{A}$, Mean response-intensity relations recorded from $\mathrm{Gnat2}^{-1-}$ mouse retinae, DA and every $15 \mathrm{~min}$ after onset of a background of $1.3 \times 10^{5} \phi_{\mu \mathrm{m}^{-2}}$ $s^{-1}$ ( $n=6$ for each condition). The data were fitted with Equation 3, with the parameters as follows: $\mathrm{DA}, R_{\max }=$ $746 \mu \mathrm{V}$ and $\phi_{1 / 2}=26.8 \phi \mu \mathrm{m}^{-2} ; 0 \mathrm{~min}, R_{\max }=18.4 \mu \mathrm{V}$ and $\phi_{1 / 2}=9.85 \times 10^{5} \phi \mu \mathrm{m}^{-2} ; 15 \mathrm{~min}, R_{\max }=$ $26.5 \mu \mathrm{V}$ and $\phi_{1 / 2}=2.02 \times 10^{5} \phi \mu \mathrm{m}^{-2} ; 30 \mathrm{~min}, R_{\max }=33.1 \mu \mathrm{V}$ and $\phi_{1 / 2}=4.45 \times 10^{4} \phi \mu \mathrm{m}^{-2} ; 45 \mathrm{~min}$, $R_{\max }=43.0 \mu \mathrm{V}$ and $\phi_{1 / 2}=4.93 \times 10^{4} \phi \mu \mathrm{m}^{-2} ; 60 \min , R_{\max }=53.4 \mu \mathrm{V}$ and $\phi_{1 / 2}=8.71 \times 10^{4} \phi \mathrm{m}^{-2}$; $75 \mathrm{~min}, R_{\max }=74.7 \mu \mathrm{V}$ and $\phi_{1 / 2}=1.37 \times 10^{5} \phi \mu \mathrm{m}^{-2} ; 90 \mathrm{~min}, R_{\max }=72.5 \mu \mathrm{V}$ and $\phi_{1 / 2}=1.55 \times 10^{5} \phi$ $\mu \mathrm{m}^{-2}$. B. Data in background light from $\boldsymbol{A}$, with the ordinate rescaled to $10 \%$ that in $\boldsymbol{A}$. C, Maximal response amplitude $\left(R_{\text {max }}\right)$ to a bright flash plotted as a function of time in the presence of background light. Flashes were $4.6 \times 10^{5}$

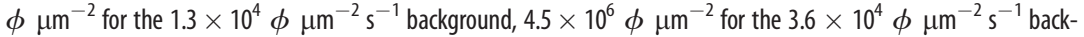
ground, and $3.4 \times 10^{6} \phi \mu \mathrm{m}^{-2}$ for the $1.3 \times 10^{5}$ and $3.6 \times 10^{5} \phi \mu \mathrm{m}^{-2} \mathrm{~s}^{-1}$ backgrounds. D, Sensitivity normalized to DA sensitivity plotted and as a function of time in background light. $C, D, n=6$ for each condition.

concentration of rhodopsin we were attempting to measure (see Materials and Methods).

Figure $5 A$ shows measurements of rhodopsin OD (noisy traces) taken at various times during exposure to $6.7 \times 10^{4} \phi$ $\mu \mathrm{m}^{-2} \mathrm{~s}^{-1}$. The data have been fitted with pigment absorbance curves (Govardovskii et al., 2000) calculated for a $\lambda_{\max }$ of $503 \mathrm{~nm}$. From these fits, we extracted values of relative peak absorbance at each of the times the measurements were made. These values are given in Figure $5 B$ for three different background light intensities of $2.6 \times 10^{4}, 6.7 \times 10^{4}$, and $6.0 \times 10^{5} \phi$ $\mu \mathrm{m}^{-2} \mathrm{~s}^{-1}$. The straight lines through the data give the value of $1-F$ calculated from Equation 4. The fraction of rhodopsin remaining (equal to the relative $\mathrm{OD}$ in the limit of low rhodopsin concentration) agreed almost perfectly with the fraction remaining calculated from the photosensitivity of the rhodopsin, the intensity of exposure, and time. There was no evidence of rhodopsin regeneration within the resolution of the MSP measurement.

\section{Rhodopsin regeneration in bright backgrounds}

The data in Figure 5 show that no significant regeneration of rhodopsin occurs for bleaches reducing the rhodopsin concentration to within $\sim 0.02$ (or $2 \%$ ) of the DA concentration, but the experiments in Figures 1-3 indicate that some pigment must nevertheless be re-forming in bright background light. To explore this apparent discrepancy, we have measured the changes in sensitivity produced by bleaching and used these measurements to estimate the rhodopsin concentration. We adopted a protocol we have previously used to measure the effect of rhodopsin bleaching for isolated mouse rods in the absence of
RPE or exogenous sources of 11-cis retinal (Nymark et al., 2012; Pahlberg et al., 2017). In those earlier experiments, we exposed mouse rods to light calculated to bleach a predetermined fraction of rhodopsin from Equation 4, and we then turned the light off and waited a period of 45-60 min to allow the sensitivity of the photoreceptors to reach steady state. We showed that the relative sensitivity of the rods at steady state after a bleach is well described by the following:

$$
\frac{S_{F}}{S_{F}^{D A}}=\frac{1-F}{1+k F}
$$

where $S_{F}$ is the sensitivity at steady state after bleaching, $S_{F}^{D A}$ is the sensitivity in the dark before the bleach, $F$ is the fraction of rhodop$\sin$ bleached, and $k$ is a constant. This equation takes into account the decrease in sensitivity produced by reduction in the concentration of rhodopsin (the decrease in quantum catch), together with light adaptation produced by activation of phototransduction by bleached pigment (Jones et al., 1996). Our thought was to make similar measurements on our preparation but with light calculated to bleach larger values of $F$ than previously. On the assumption that rods will continue to behave according to Equation 5, we hoped to use the change in sensitivity to estimate the actual fraction of rhodopsin remaining in the rod, including any regeneration that may have occurred.

The results of these experiments are given in Figure 6. The Gnat $2^{-1-}$ retinae were exposed to steady light of intensity $3.6 \times 10^{5} \phi \mu \mathrm{m}^{-2} \mathrm{~s}^{-1}$ as in Figures 1 and 3, but for the times indicated in Figure 6. At the cessation of each exposure, we waited $45-60 \mathrm{~min}$ for the rods to reach steady state and then measured the sensitivity, in a manner identical to our previous work for single rods (Nymark et al., 2012; Pahlberg et al., 2017). Sokolov et al. (2002) showed that movement of transducin back into the outer segment is much slower than translocation outward, having a time for half-completion of $2.5 \mathrm{~h}$ (see also Zhang et al., 2011). Over the time course of these experiments, the great majority of transducin moving to the inner segment will have remained there.

The changes in sensitivity and response amplitude are given in Figure $6 A$ for light exposures ranging from 2 to $180 \mathrm{~min}(3 \mathrm{~h})$. In Figure $6 B$, we show the relative sensitivity at each of the times at which measurements were made. The dashed red line is Equation 5 with Equation 4 substituted for $F$ to account for the loss of pigment. For changes of relative sensitivity up to $\sim 10^{-4}$, this line gave a good fit to the data much as in previous work, although the value of the constant $k$ (70) was somewhat larger in our whole-retina preparation than for single rods recorded with suction electrodes (35, Nymark et al., 2012; 24, Pahlberg et al., 2017). Beyond a relative sensitivity of $10^{-4}$, the data were better fit by a curve for which the fraction of rhodopsin remaining was no longer given by Equation 4 but was larger than predicted by this equation. This altered unbleached fraction is shown in Figure $6 \mathrm{C}$. The dashed red line again gives the prediction of Equation 4 for the fraction of pigment remaining $(1-F)$, and the 
black continuous line is the concentration of rhodopsin required to fit the sensitivity measurements in Figure $6 \mathrm{~B}$ for long exposures to the background light.

On the assumption that the rod continues to behave according to Equation 5 for longer background exposures, the difference between the red dashed and black continuous lines in Figure $6 C$ gives the amount of additional rhodopsin present in the rods, which must have been formed by some process of regeneration. As we show in Figure 7, this regeneration seems not to occur in darkness but only in the presence of illumination. We therefore modeled this process by allowing bleached rhodopsin either to re-form rhodopsin with a light-dependent rate constant $k_{r}$, or to decay into free opsin and atRAL with a rate constant $k_{d}$ (see Eqs. 2a and 2b). The fraction of rhodopsin calculated by the model is then given as the black continuous line in Figure 6C. The value of $k_{r}$ that we obtained to the best fit of

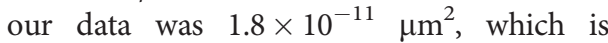
$\sim 0.3 \%$ of the photosensitivity of rhodopsin (Woodruff et al., 2004). These data indicate that the amount of additional pigment that is formed is small and can only be detected when the calculated fraction of pigment drops to $<\sim 1 \%$. From that point onward, some process produces enough additional rhodopsin to keep the pigment concentration nearly constant, so that sensitivity never drops below $10^{-5}$ to $10^{-4}$ of that in darkness.

Similar data were obtained from single rods recorded with suction electrodes (Fig. 2C,D). Rods were exposed for $60 \mathrm{~min}$ to a $565 \mathrm{~nm}$ background light delivering $10^{6} \phi \mu \mathrm{m}^{-2} \mathrm{~s}^{-1}$. For this intensity and duration, Equation 4 predicts that the fraction of pigment remaining should have been $\sim 10^{-9}$, or a single molecule of rhodopsin every 15-20 rods. Relative sensitivity decreases to $\sim 10^{-5}$, much as for the $180 \mathrm{~min}$ exposure to the $3.6 \times 10^{5} \phi$ $\mu \mathrm{m}^{-2} \mathrm{~s}^{-1}$ background in Figure 6. These experiments confirm that regeneration can maintain the rhodopsin concentration at $0.1 \%-1 \%$ that in darkness, sufficient to allow the rods to continue to respond to bright, maintained illumination at least for several hours and perhaps indefinitely. And since the experiments of Figure $2 C, D$ were done with suction-electrode recording on single rods, this process of regeneration must be occurring within the rod itself.

\section{Possible mechanisms of regeneration}

How does this regeneration occur? All of the experiments in Figures 1-4 were done either on single photoreceptors or with isolated retina. Every effort was made to remove all of the RPE when preparing the retina for recording. The background lights were chosen to be between 560 and $570 \mathrm{~nm}$. At these wavelengths, there should be little activation of isomerization from retinal condensed with PE to form the retinyl-lipid, N-retinylidene-PE (N-ret-PE) (Kaylor et al., 2017) or retinal G-proteincoupled receptor opsin (Morshedian et al., 2019). The protocols of our experiments seem therefore to have eliminated the principal known mechanisms of 11-cis retinal chromophore regeneration.

Since, however, the amount of additional rhodopsin required in Figure $6 \mathrm{C}$ is quite small, it seemed to us possible that some
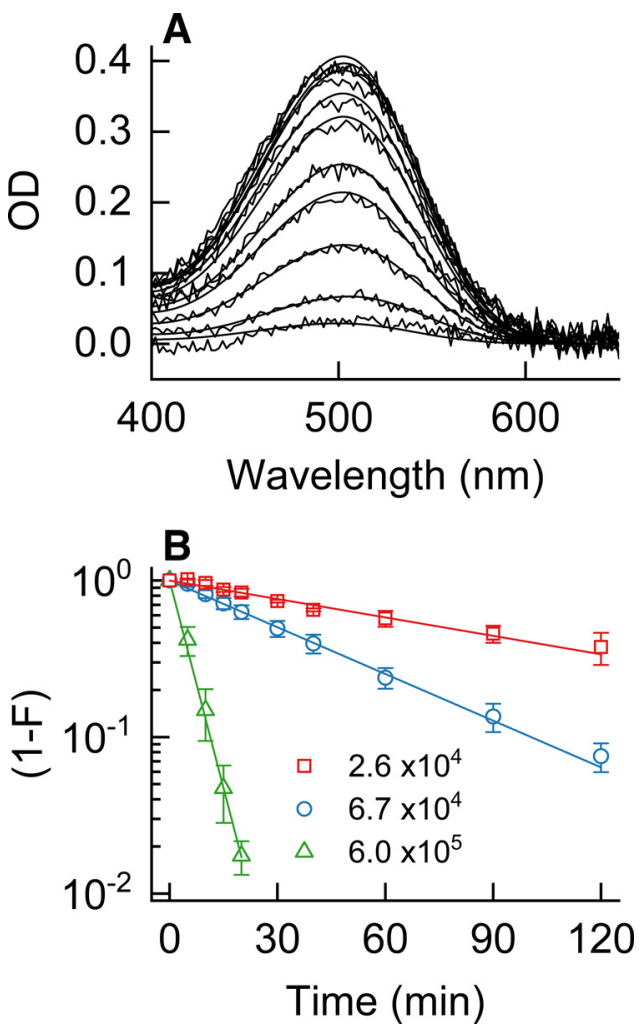

Figure 5. MSP measurements of OD of WT mouse rods during pigment bleaching. $\boldsymbol{A}$, Examples of absorbance spectra recorded first in DA retina and then after exposure to 570

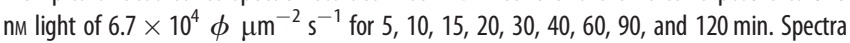
were fitted with rhodopsin templates (Govardovskii et al., 2000) with $\lambda_{\max }=503 \mathrm{~nm}$. $\boldsymbol{B}$, Bleaching of rhodopsin expressed as normalized $O D$ at $500 \mathrm{~nm}$ from recordings as in $\boldsymbol{A}$ for background intensities of $2.6 \times 10^{4} \phi \mu^{-2} \mathrm{~s}^{-1}$ (red squares, $n=3$ ), $6.7 \times 10^{4} \phi$ $\mu \mathrm{m}^{-2} \mathrm{~s}^{-1}$ (blue circles, $n=5$ ), and $6.0 \times 10^{5} \phi \mu \mathrm{m}^{-2} \mathrm{~s}^{-1}$ (green triangles, $n=3$ ). Lines indicate fraction of pigment remaining $(1-F)$ calculated from Equation 4. 

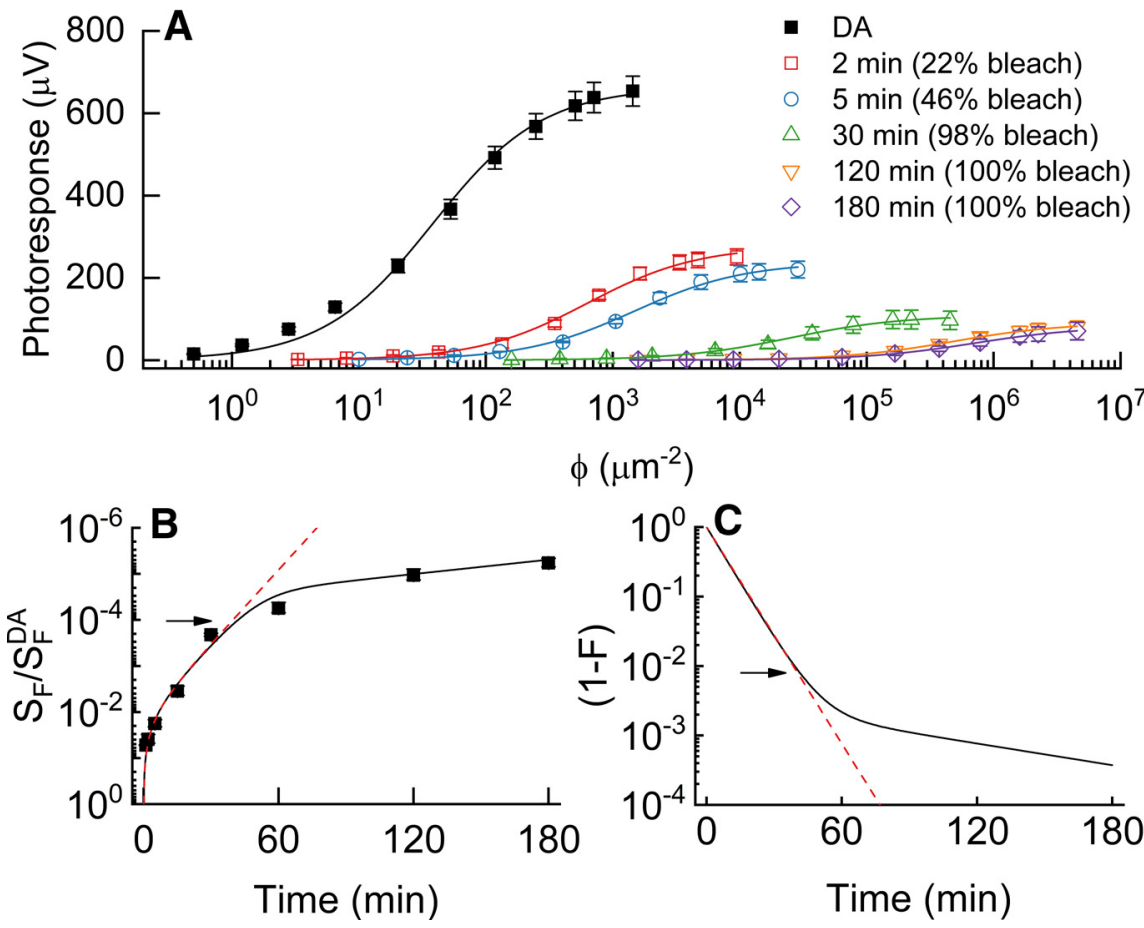

Figure 6. Sensitivity and rhodopsin concentration after long exposures to bright light. $\boldsymbol{A}$, Responses were recorded as in Figure 1 first in darkness (DA, $n=24)$. Retinae were then exposed for a variable duration (as indicated in the figure) to $560 \mathrm{~nm}$ light of $3.6 \times 10^{5} \phi \mu \mathrm{m}^{-2} \mathrm{~s}^{-1}$ and returned to darkness for an additional 45-60 min to allow the rods to come to steady state. Data from bleached conditions are averages from 3 retinae for each condition and give response amplitude as a function of flash strength. $\boldsymbol{B}$, Sensitivity from $\boldsymbol{A}$, normalized to DA sensitivity. Dashed red line is Equation 5, with $k=70$ and $1-F$ calculated from Equation 4. Black line is also Equation 5, but with $1-F$ taken from its value inferred from the black line in $\boldsymbol{C}$. Arrow points to the sensitivity where the two lines diverge at $\sim 0.8 \%-1 \%$ of DA rhodopsin concentration. $\boldsymbol{C}$, Inferred concentration of rhodopsin $(1-F)$. Dashed red line is $1-F$ from Equation 4 , assuming no regeneration. Black line is $1-F$ calculated from the numerical solution to Equations $2 \mathrm{a}$ and $2 \mathrm{~b}$, with the constants $k_{d}=2.0 \times 10^{-4} \mathrm{~s}^{-1}$ and $k_{r}=$ $1.8 \times 10^{-11} \mu \mathrm{m}^{2}$. Arrow points to the value of $1-F$ where the two curves diverge.

residual process might supply chromophore to the rods. To see whether this mechanism operates in darkness, we exposed reti-

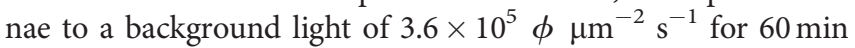
and then measured sensitivity as a function of time in darkness. These data are shown in Figure $7 A, B$. The black circles give the response-intensity values just before turning the background off, and the other curves show responses in darkness from 2-90 min. These curves seem to indicate that very little change in sensitivity occurs after the light is turned off.

We quantified these changes from Figure $7 A, B$ in the same way as for Figure $3 D$ and plotted the relative sensitivity $S_{F} / S_{F}^{D A}$ as a function of time in Figure $7 C$. The dotted vertical line indicates the time when the background light was extinguished. Sensitivity increased by a factor of $\sim 2$ within the first $2 \mathrm{~min}$, probably at least in part reflecting the removal of light adaptation after turning off the illumination. From 2 until $90 \mathrm{~min}$, the sensitivity was nearly constant, varying by no more than a factor of 1.5. These data provide no evidence of any process in darkness that regenerates a significant amount of rhodopsin.

Another possibility is that visual pigment is regenerated by reversed photoisomerization of atRAL in the light. To investigate this possibility, we illuminated mouse retinas with a $560 \mathrm{~nm}$ background at an intensity of $10^{6} \phi \mu^{-2} \mathrm{~s}^{-1}$. At 30, 60, and $90 \mathrm{~min}$, the retinas were removed and the retinoid content was evaluated with HPLC, which has greater sensitivity for small changes in retinoid species. We measured levels of both 11-cis and 9-cis retinals because both can form visual pigments (see, e.g., Hurley et al., 1977). The amount of 11-cis retinal was between 0.02 and 0.03 of that in darkness at all three time points of background exposure. The sum of the 11-cis and 9-cis retinal amounts varied from 0.04 to 0.06 of the amount of 11-cis retinal in the dark. Because these values did not change greatly with time, they may reflect a steady-state during the bright continuous illumination used in this experiment. Cones in mouse make up only $\sim 3 \%$ of the total photoreceptor population (Carter-Dawson and LaVail, 1979) and have outer-segment volumes $\sim 0.4$ that of rods (Nikonov et al., 2006). The fraction of chromophore coming from the cones is therefore unlikely to have exceeded $1 \%$, which we have indicated with the dashed horizontal line in Figure 7D. Most of the additional 11-cis and 9-cis retinals in Figure $7 D$ are likely to have been produced by isomerization of atRAL released by bleaching of rhodopsin. This regeneration of chromophore could have originated from one or more of a number of mechanisms, including N-ret-PE isomerization, photoisomerization of unbound atRAL (see, e.g., Kropf and Hubbard, 1970), or reversal of one of the intermediates of rhodopsin bleaching, such as meta I, meta II, or meta III. We review these possibilities and their possible physiological significance below.

\section{Discussion}

Our experiments show that rods continue to respond even in the brightest background light. Responses are initially small but gradually increase over a period of $90 \mathrm{~min}$ to become $\sim 10 \%$ of the maximum response in a DA preparation (Figs. 1-3). Rods avoid saturation because the $G$ protein transducin slowly moves from the rod outer segment to the inner segment under bright illumination, which reduces the gain of phototransduction and restores a small fraction of cGMP and circulating current. If this movement is impeded, rod responses recover more slowly and are smaller. In addition, regeneration prevents the rhodopsin level from ever falling to $<\sim 0.1 \%$ of its dark level or $6 \times 10^{4}$ rhodopsins per rod (Figs. 5 and 6). Although the mechanism of regeneration is unclear, our experiments show that negligible regeneration occurs in our preparations in darkness after the light is extinguished (Fig. $7 A-C$ ) but that visual pigment can be regenerated during continuous light exposure (Fig. 7D), apparently within the rod itself (Fig. 2C,D).

\section{Return of light responses in bright light}

The results in Figures 1-3 confirm previous work from TikidjiHamburyan et al. (2017) that mouse rods can recover some response amplitude even in very bright illumination. Because we studied responses in a fixed background intensity over a prolonged period, we were able to provide a more detailed description of this effect. Recovery was greater for backgrounds above a threshold of $\sim 10^{4} \phi \mu \mathrm{m}^{-2} \mathrm{~s}^{-1}$, but we did not observe any clear correlation between background intensity and the rate or extent of increase of $R_{\max }$ once this threshold was exceeded (Fig. 3D) 
(see Lobanova et al., 2007, 2010). Although the rate of formation of light-activated transducin would be greater in brighter light, the amount free in the outer segment and able to diffuse over an interval of 45-60 min may be sufficiently similar at these light intensities to permit diffusion at similar rates.

All of the experiments in Figures 1-3 were done either on isolated rods or on the isolated retina. In the intact eye, however, rhodopsin is regenerated in the RPE with a time constant in mouse of between 30 (Majumder et al., 2013) and $50 \mathrm{~min}$ (Lamb and Pugh, 2004). It might be thought that the greater concentration of rhodopsin in the intact eye might produce more persistent activation of phosphodiesterase and keep the rods in saturation in bright illumination. To explore this possibility, we have calculated the fraction of rhodopsin bleached at steady state in the intact eye for a range of light intensities, roughly equivalent to illumination between 100 and 10,000 lux, which spans the ambient light level from dawn or dusk to bright sunlight (Burns and Pugh, 2014). The steady-state fraction bleached can be calculated from the following:

$$
F=\frac{\phi P \tau}{1+\phi P \tau}
$$

where $\phi$ and $P$ are defined as for Equation 4 and $\tau$ is the regeneration time constant in seconds. These calculations are given in Table 1 and show that, in the intact mouse retina, the fraction bleached varies from $\sim 51 \%$ to as much as $99.9 \%$, depending on the light intensity and the assumption made about the regeneration time constant.

We also show in Table 1 the fraction bleached in our isolatedretina preparations as a function of time, in two representative light intensities of $3.6 \times 10^{4}$ and $1.3 \times 10^{5} \phi \mu \mathrm{m}^{-2} \mathrm{~s}^{-1}$. The values of fraction bleached at these two light intensities at the different times given in the table span the range of steady-state bleaches in the intact eye during daylight. If unbleached rhodopsin in the isolated retina is insufficient to saturate phototransduction after $90 \mathrm{~min}$ at these two intensities, as our data clearly show, then unbleached rhodopsin at steady state in the intact eye is unlikely to do so either. We cannot exclude the possibility that some other feature of transduction (e.g., the rate of transducin translocation) can differ between the intact eye and the isolated retina, but rod signals in bright light have been detected in intact preparations in horizontal cells and ganglion cells (Borghuis et al., 2018) as well as in the lateral geniculate nucleus (TikidjiHamburyan et al., 2017). In addition, previous work has shown that the increase in rod response observed in bright light continues to occur in the presence of exogenous 9-cis retinal (TikidjiHamburyan et al., 2017). Thus, we think it very likely that the mechanism we have described in isolated retina also functions to prevent saturation in the intact eye.

\section{Role of transducin translocation}

Our experiments indicate that the primary cause of the slow increase in circulating current and sensitivity in bright light is
Table 1. Percent fraction bleached with and without rhodopsin regeneration ${ }^{a}$

\begin{tabular}{lll}
\hline Retina with pigment epithelium, steady-state bleaching & \\
$I\left(\phi \mu \mathrm{m}^{-2} \mathrm{~s}^{-1}\right)$ & $\% F(\tau=30 \mathrm{~min})$ & $\% F(\tau=50 \mathrm{~min})$ \\
\hline $10^{5}$ & 50.6 & 63 \\
$10^{6}$ & 91.1 & 94.4 \\
$10^{7}$ & 99.0 & 99.9 \\
\hline Isolated retina, no regeneration & \\
\hline Time of exposure (min) & $I\left(3.6 \times 10^{4} \phi \mu \mathrm{m}^{-2} \mathrm{~s}^{-1}\right) /\left(1.3 \times 10^{5} \phi \mu \mathrm{m}^{-2} \mathrm{~s}^{-1}\right)$ \\
30 & 31 & 74 \\
60 & 52 & 93 \\
90 & 67 & 98 \\
\hline
\end{tabular}

${ }^{a} /$, Intensity (units of equivalent photons $\mu \mathrm{m}^{-2} \mathrm{~s}^{-1}$ at the $\lambda_{\max }$ of the rod photopigment); $F$, fraction bleached from Equations 4 and 6 .

likely to be the movement of transducin out of the outer segment. The evidence is first, that the intensity dependence, time course of increase, and magnitude of both sensitivity and $R_{\max }$ in Figures 1-3 were in close correspondence to those observed from immunohistochemical studies of transducin translocation (Sokolov et al., 2002; Lobanova et al., 2007, 2010). We showed, in addition, that the ability of rods to avoid saturation is reduced in the $A 3 C^{+}$mouse (Fig. 4). This animal lacks normal $\mathrm{G} \alpha_{\mathrm{t}}$ but instead contains a $\mathrm{G} \alpha_{\mathrm{t}}$ with an additional, artificial S-palmitoylation site, increasing its binding affinity to disk membranes compared with normal $\mathrm{G} \alpha$. Although some transducin translocation can still occur in this mouse (Majumder et al., 2013), the return of the light response was impeded (Fig. 4). We believe that, if we had been able to inhibit translocation completely, rods in bright light would have remained saturated with no increase in circulating current or responses to incremental flashes. Although other mechanisms, such as translocation of arrestin or recoverin (Sampath et al., 2005; Strissel et al., 2005; Artemyev, 2008; 
Pearring et al., 2013), may also contribute to recovery of rod responses (Tikidji-Hamburyan et al., 2017), we believe their contribution to be less important.

\section{Rhodopsin bleaching and regeneration}

Our recordings show that rods can continue to respond for long periods in a background light so bright, that fewer than one rhodopsin molecule would be left per rod in the absence of rhodopsin regeneration. The amount of regeneration cannot be detected with the resolution of MSP, which is $\sim 2 \%$ of the dark concentration of rhodopsin (Fig. 5). When, however, we used the sensitivity of the rod after exposure to a bright background as a measure of the rhodopsin content, we were able to show that sufficient regeneration can occur to maintain the rhodopsin concentration to between $0.1 \%$ and $1 \%$ of the dark level.

How is this rhodopsin regenerated? Our experiments show that there is little regeneration in darkness (Fig. $7 A-C$ ) but that some 9-cis and 11-cis retinal can be formed during continuous light exposure (Fig. 7D), and that this regeneration appears to be occurring within the confines of a single rod, probably within the outer segment (Fig. 2C,D). One possibility is simple photoisomerization of atRAL (Kropf and Hubbard, 1970), but the $\lambda_{\text {max }}$ of atRAL in solution is likely to be shorter than $400 \mathrm{~nm}$ and would be little affected by the wavelengths of background light used in our experiments ( 560 and $565 \mathrm{~nm}$ ). The $\lambda_{\max }$ of atRAL can be shifted to $450 \mathrm{~nm}$ if it is condensed with PE to form the retinyllipid, N-retinylidene-PE (N-ret-PE) (Kaylor et al., 2017). Although little isomerization from the N-ret-PE pathway would be expected at long wavelengths, a small contribution cannot be excluded. Light could also photoreverse one of the pigment intermediates of bleaching, but the concentration of these intermediates is likely to be small during long exposures to bright light (Chen et al., 2009; Blakeley et al., 2011; Nymark et al., 2012; Frederiksen et al., 2016). Other possibilities, such as RPE clinging to the isolated retina or regeneration by retinal $G$ proteincoupled receptor opsin (Morshedian et al., 2019), can probably be excluded because the experiments of Figure 2 show that regeneration appears to occur within the rod itself.

Although we cannot say how rods are able to maintain the rhodopsin concentration in very bright light, we can say something about the significance of this mechanism. Equation 6 predicts that the steady-state concentration of rhodopsin would fall to $<1 \%$ that of darkness in a continuous light of intensity in excess of $10^{7} \phi \mu \mathrm{m}^{-2} \mathrm{~s}^{-1}$, or $10^{15} \phi \mathrm{cm}^{-2} \mathrm{~s}^{-1}$ (see Table 1). In humans, the time constant of regeneration is only $400 \mathrm{~s}$ (Alpern, 1971), which would increase this estimated intensity by a factor of $\sim 5$. It is unlikely that we or any vertebrate would willingly view light this bright directly for a prolonged period. It is however remarkable that for light even brighter, some further mechanism of regeneration within the rod can prevent the amount of pigment from dropping even lower.

\section{Saturation and photoreceptor degeneration}

Although it is possible to detect rod input in bright light to other parts of the visual system (Tikidji-Hamburyan et al., 2017; Borghuis et al., 2018), there is little evidence that signals from rods contribute to visual perception under photopic conditions of illumination. The rod responses we have recorded in bright backgrounds are relatively small and have slower kinetics than responses of cones (Nikonov et al., 2006; Ingram et al., 2019). It seems unlikely that the visual system would use these responses in preference or even in addition to the much bigger and faster responses of cones at intensities $>10^{5} \phi \mu \mathrm{m}^{-2} \mathrm{~s}^{-1}$ incident on the retina, the equivalent of a few hundred lux incident on the eye (Burns and Pugh, 2014).

We think instead that the primary function of the recovery of the response is neuroprotective. We have shown that the return of the response can be largely prevented in the $\mathrm{A}^{+} \mathrm{C}^{+}$mouse by reducing the level of translocation of transducin. It is significant that the rods of $\mathrm{ABC}^{+}$mice slowly degenerate, and that degeneration is prevented by keeping the animals in darkness (Majumder et al., 2013). We believe that this degeneration is a direct consequence of reduction in the translocation of transducin, which prevents the reopening of the outer-segment cGMPgated channels in prolonged bright light (Fig. 4). Maintained closure of channels during continuous real or equivalent light is known to produce photoreceptor degeneration, perhaps as a consequence of too low a concentration of outer-segment $\mathrm{Ca}^{2+}$ (Fain and Lisman, 1999; Woodruff et al., 2003; Lem and Fain, 2004; Burns and Arshavsky, 2005; Fain, 2006; Arshavsky and Burns, 2012; Majumder et al., 2013; Pearring et al., 2013). We think that avoidance of saturation in bright light may be one of the principal mechanisms the eye uses to keep outer-segment channels from ever closing for too long a time. Because of this important mechanism, we are able to use our eyes under virtually any condition of illumination without damaging our rods.

\section{References}

Aguilar M, Stiles WS (1954) Saturation of the rod mechanism of the retina at high levels of stimulation. Optica Acta 1:59-65.

Alpern M (1971) Rhodopsin kinetics in the human eye. J Physiol 217:447471.

Arshavsky VY, Burns ME (2012) Photoreceptor signaling: supporting vision across a wide range of light intensities. J Biol Chem 287:1620-1626.

Artemyev NO (2008) Light-dependent compartmentalization of transducin in rod photoreceptors. Mol Neurobiol 37:44-51.

Baylor DA, Lamb TD, Yau KW (1979) The membrane current of single rod outer segments. J Physiol 288:589-611.

Blakeley LR, Chen C, Chen CK, Chen J, Crouch RK, Travis GH, Koutalos Y (2011) Rod outer segment retinol formation is independent of Abca4, arrestin, rhodopsin kinase, and rhodopsin palmitylation. Invest Ophthalmol Vis Sci 52:3483-3491.

Borghuis BG, Ratliff CP, Smith RG (2018) Impact of light-adaptive mechanisms on mammalian retinal visual encoding at high light levels. J Neurophysiol 119:1437-1449.

Burns M, Arshavsky V (2005) Beyond counting photons: trials and trends in vertebrate visual transduction. Neuron 48:387-401.

Burns ME, Pugh EN Jr (2014) Visual transduction by rod and cone photoreceptors. In: The new visual neurosciences (Chalupa LM, Werner JH, eds), pp 7-19. Cambridge MA: Massachusetts Institute of Technology.

Carter-Dawson LD, LaVail MM (1979) Rods and cones in the mouse retina: I. Structural analysis using light and electron microscopy. J Comp Neurol 188:245-262.

Chen C, Blakeley LR, Koutalos Y (2009) Formation of all-trans retinol after visual pigment bleaching in mouse photoreceptors. Invest Ophthalmol Vis Sci 50:3589-3595.

Dartnall HJ (1968) The photosensitivities of visual pigments in the presence of hydroxylamine. Vision Res 8:339-358.

Fain GL (1976) Sensitivity of toad rods: dependence on wave-length and background illumination. J Physiol 261:71-101.

Fain GL (2006) Why photoreceptors die (and why they don't). Bioessays 28:344-354.

Fain GL, Lisman JE (1999) Light, $\mathrm{Ca}^{2+}$, and photoreceptor death: new evidence for the equivalent-light hypothesis from arrestin knockout mice. Invest Ophthalmol Vis Sci 40:2770-2772.

Field GD, Rieke F (2002) Nonlinear signal transfer from mouse rods to bipolar cells and implications for visual sensitivity. Neuron 34:773-785.

Frederiksen R, Boyer NP, Nickle B, Chakrabarti KS, Koutalos Y, Crouch RK, Oprian D, Cornwall MC (2012) Low aqueous solubility of 11-cis-retinal limits the rate of pigment formation and dark adaptation in salamander rods. J Gen Physiol 139:493-505. 
Frederiksen R, Nymark S, Kolesnikov AV, Berry JD, Adler L, Koutalos Y, Kefalov VJ, Cornwall MC (2016) Rhodopsin kinase and arrestin binding control the decay of photoactivated rhodopsin and dark adaptation of mouse rods. J Gen Physiol 148:1-11.

Govardovskii VI, Fyhrquist N, Reuter T, Kuzmin DG, Donner K (2000) In search of the visual pigment template. Vis Neurosci 17:509-528.

Gross OP, Pugh EN Jr, Burns ME (2012) Calcium feedback to cGMP synthesis strongly attenuates single-photon responses driven by long rhodopsin lifetimes. Neuron 76:370-382.

Hurley JB, Ebrey TG, Honig B, Ottolenghi M (1977) Temperature and wavelength effects on the photochemistry of rhodopsin, isorhodopsin, bacteriorhodopsin and their photoproducts. Nature 270:540-542.

Ingram NT, Sampath AP, Fain GL (2019) Voltage-clamp recordings of light responses from wild-type and mutant mouse cone photoreceptors. J Gen Physiol 151:1287-1299.

Jones GJ, Cornwall MC, Fain GL (1996) Equivalence of background and bleaching desensitization in isolated rod photoreceptors of the larval tiger salamander. J Gen Physiol 108:333-340.

Kaylor JJ, Xu T, Ingram NT, Tsan A, Hakobyan H, Fain GL, Travis GH (2017) Blue light regenerates functional visual pigments in mammals through a retinyl-phospholipid intermediate. Nat Commun 8:16.

Kropf A, Hubbard R (1970) The photoisomerization of retinal. Photochem Photobiol 12:249-260.

Lamb TD, McNaughton PA, Yau KW (1981) Spatial spread of activation and background desensitization in toad rod outer segments. J Physiol 319:463-496.

Lamb TD, Pugh EN Jr (2004) Dark adaptation and the retinoid cycle of vision. Prog Retin Eye Res 23:307-380.

Lem J, Fain GL (2004) Constitutive opsin signaling: night blindness or retinal degeneration? Trends Mol Med 10:150-157.

Lobanova ES, Finkelstein S, Song H, Tsang SH, Chen CK, Sokolov M, Skiba NP, Arshavsky VY (2007) Transducin translocation in rods is triggered by saturation of the GTPase-activating complex. J Neurosci 27:11511160 .

Lobanova ES, Herrmann R, Finkelstein S, Reidel B, Skiba NP, Deng WT, Jo R, Weiss ER, Hauswirth WW, Arshavsky VY (2010) Mechanistic basis for the failure of cone transducin to translocate: why cones are never blinded by light. J Neurosci 30:6815-6824.

Majumder A, Pahlberg J, Boyd KK, Kerov V, Kolandaivelu S, Ramamurthy V, Sampath AP, Artemyev NO (2013) Transducin translocation contributes to rod survival and enhances synaptic transmission from rods to rod bipolar cells. Proc Natl Acad Sci USA 110:12468-12473.

Makino CL, Dodd RL, Chen J, Burns ME, Roca A, Simon MI, Baylor DA (2004) Recoverin regulates light-dependent phosphodiesterase activity in retinal rods. J Gen Physiol 123:729-741.

Makous WI (2003) Scotopic vision. In: Visual neurosciences, pp 838-850. Cambridge MA: Massachusetts Institute of Technology.

Mendez A, Burns ME, Sokal I, Dizhoor AM, Baehr W, Palczewski K, Baylor DA, Chen J (2001) Role of guanylate cyclase-activating proteins (GCAPs) in setting the flash sensitivity of rod photoreceptors. Proc Natl Acad Sci USA 98:9948-9953

Morshedian A, Fain GL (2017) Light adaptation and the evolution of vertebrate photoreceptors. J Physiol 595:4947-4960.

Morshedian A, Woodruff ML, Fain GL (2018) Role of recoverin in rod photoreceptor light adaptation. J Physiol 596:1513-1526.

Morshedian A, Kaylor JJ, Ng SY, Tsan A, Frederiksen R, Xu T, Yuan L, Sampath AP, Radu RA, Fain GL, Travis GH (2019) Light-driven regeneration of cone visual pigments through a mechanism involving RGR opsin in Muller glial cells. Neuron 102:1172-1183.e1175.

Naarendorp F, Esdaille TM, Banden SM, Andrews-Labenski J, Gross OP, Pugh EN Jr (2010) Dark light, rod saturation, and the absolute and incremental sensitivity of mouse cone vision. J Neurosci 30:12495-12507.

Nickell S, Park PS, Baumeister W, Palczewski K (2007) Three-dimensional architecture of murine rod outer segments determined by cryoelectron tomography. J Cell Biol 177:917-925.

Nikonov SS, Kholodenko R, Lem J, Pugh EN Jr (2006) Physiological features of the S- and M-cone photoreceptors of wild-type mice from single-cell recordings. J Gen Physiol 127:359-374.

Nymark S, Frederiksen R, Woodruff ML, Cornwall MC, Fain GL (2012) Bleaching of mouse rods: microspectrophotometry and suction-electrode recording. J Physiol 590:2353-2364.

Pahlberg J, Frederiksen R, Pollock GE, Miyagishima KJ, Sampath AP, Cornwall MC (2017) Voltage-sensitive conductances increase the sensitivity of rod photoresponses following pigment bleaching. J Physiol 595:3459-3469.

Pearring JN, Salinas RY, Baker SA, Arshavsky VY (2013) Protein sorting, targeting and trafficking in photoreceptor cells. Prog Retin Eye Res 36:2451.

Radu RA, Hu J, Peng J, Bok D, Mata NL, Travis GH (2008) Retinal pigment epithelium-retinal $\mathrm{G}$ protein receptor-opsin mediates light-dependent translocation of all-trans-retinyl esters for synthesis of visual chromophore in retinal pigment epithelial cells. J Biol Chem 283:19730-19738.

Ronning KE, Allina GP, Miller EB, Zawadzki RJ, Pugh EN Jr, Herrmann R, Burns ME (2018) Loss of cone function without degeneration in a novel Gnat2 knock-out mouse. Exp Eye Res 171:111-118.

Sampath AP, Strissel KJ, Elias R, Arshavsky VY, McGinnis JF, Chen J, Kawamura S, Rieke F, Hurley JB (2005) Recoverin improves rod-mediated vision by enhancing signal transmission in the mouse retina. Neuron 46:413-420.

Sokolov M, Lyubarsky AL, Strissel KJ, Savchenko AB, Govardovskii VI, Pugh EN Jr, Arshavsky VY (2002) Massive light-driven translocation of transducin between the two major compartments of rod cells: a novel mechanism of light adaptation. Neuron 34:95-106.

Strissel KJ, Lishko PV, Trieu LH, Kennedy MJ, Hurley JB, Arshavsky VY (2005) Recoverin undergoes light-dependent intracellular translocation in rod photoreceptors. J Biol Chem 280:29250-29255.

Tamura T, Nakatani K, Yau KW (1991) Calcium feedback and sensitivity regulation in primate rods. J Gen Physiol 98:95-130.

Tikidji-Hamburyan A, Reinhard K, Storchi R, Dietter J, Seitter H, Davis KE, Idrees S, Mutter M, Walmsley L, Bedford RA, Ueffing M, Ala-Laurila P, Brown TM, Lucas RJ, Münch TA (2017) Rods progressively escape saturation to drive visual responses in daylight conditions. Nat Commun 8:1813.

Vinberg F, Kolesnikov AV, Kefalov VJ (2014) Ex vivo ERG analysis of photoreceptors using an in vivo ERG system. Vision Res 101:108-117.

Woodruff ML, Wang Z, Chung HY, Redmond TM, Fain GL, Lem J (2003) Spontaneous activity of opsin apoprotein is a cause of Leber congenital amaurosis. Nat Genet 35:158-164.

Woodruff ML, Lem J, Fain GL (2004) Early receptor current of wild-type and transducin knockout mice: photosensitivity and light-induced $\mathrm{Ca}^{2+}$ release. J Physiol 557:821-828.

Zhang HR, Constantine S, Vorobiev Y, Chen J, Seetharaman YJ, Huang R, Xiao GT, Montelione CD, Gerstner MW, Davis G, Inana FG, Whitby EM, Jorgensen CP, Hill L, Tong W Baehr (2011) UNC119 is required for $\mathrm{G}$ protein trafficking in sensory neurons. Nat Neurosci 14:874-880. 